\title{
DE DONZELA À CORTESÃ: A MULHER EM LUCÍOLA
}

\section{DE DONCELLA A CORTESANA: LA MUJER EN LUCÍOLA}

\author{
Higor Miranda Cavalcante ${ }^{1}$ \\ Valdeci Batista de Melo Oliveira ${ }^{2}$
}

Resumo: O presente artigo visa analisar alguns aspectos da poética que performam o romance Lucíola (1862), obra romântica de ficção urbana de José de Alencar. O que no texto se considera é a figuração que o romance faz da cortesã na sociedade carioca do século XIX e os valores defendidos pelos personagens, dentro do Romantismo. É essa convenção estética que norteia a produção da obra, cujo fio condutor se centra no discurso, nas ações e no retrato físico e psicológico da personagem central: Lucíola. Essa protagonista, ao início sendo a púbere Maria da Glória, depois decaída na perdição como Lúcia-Lúcifer e, enfim, é apresentada a sua redenção para a boa Maria Lúcia, angélica. A ambiência social de frequentação das personagens é o mundo urbano da corte do Rio de Janeiro, do século XIX, na mais pura expressão do atavismo provinciano e suas idiossincrasias, seus valores e suas figuras do patriarcado.

Palavras-chave: Romantismo; Sociedade; Influência.

Resumen: El presente artículo tiene como objetivo analizar los principales aspectos que influenciaron la producción de la obra romántica de ficción urbana Lucíola (1862), de José de Alencar, llevando en consideración el análisis sociológico que la sociedad del siglo XIX tenía sobre la cortesana y el periodo literario, Romantismo, en Brasil, en que el texto fue escrito. El Texto trae el análisis de tres periodos en que podemos dividir el estado físico y psicológico del personaje central: Maria pura, Lúcia-Lúcifer, Maria renovada. Objetivando un mejor embasamiento histórico y sociológico y la ubicación del lector en el periodo histórico-literario, este artículo trae un breve estudio de los aspectos literarios de José de Alencar y del periodo en que la obra fue escrita.

Palabras clave: Romantismo; Sociedad; Influencia.

1 Acadêmico de Letras - Português/Espanhol na Universidade Estadual do Oeste do Paraná - UNIOESTE. E-mail: contato. hmc@live.com

2 Professora Associada da Universidade Estadual do Oeste do Paraná - UNIOESTE. E-mail: valzinha.mello@hotmail.com 


\section{INTRODUÇÃO}

O movimento intelectual Sturm und Drang (1760) engendrou o espírito romântico na Europa com intensidade suficiente para, meio século depois, animar a verve dos escritores românticos no Brasil. Sabemos que, no Brasil, o Romantismo começou em 1836 com a publicação da obra inaugural Suspiros Poéticos e Saudades, de Gonçalves de Magalhães, e se estendeu até 1881, com "ímpetos" de liberdade sem peias, somado às "tempestades" do coração e da alma, formulações literárias expressas muito mais nos devaneios elegantes e no reino da fantasia que na efetividade do sangue e do suor dos negros submetidos à escravidão brutal, e que levaram autores românticos a enunciarem o desejo de firmar uma nacionalidade forjada pelo retrato da vida privada ou pela exuberância da fauna e da flora - questões então desconhecidas e veladas dos olhos urbanos -, para com elas construir e alimentar o imaginário urbano do nosso público leitor. Desse modo, a visada de constituição de uma identidade nacional brasileira passava ao largo dos óbices que faziam do país um arremedo de modernidade, óbices à época pouco percebidos como tais pelos pensadores/autores na ativa. Sobre essa contradição, diga-se mais, diga-se que Manuel Antônio de Almeida elabora e publica a sua original Memórias de um Sargento de Milícias (1852), assim figurando esses óbices com requintes de mestria, isso dez anos antes do romance Lucíola. Isso, mutatis mutandis, corresponderia a anunciar o lançamento de um veículo puxado a cavalo dez anos depois de do lançamento do primeiro automóvel.

De volta ao romantismo, vemos que a falta de modelos para as peculiaridades da nossa organização social foi mais contornável na lírica, que conseguiu ultrapassar os obstáculos seguindo as "[...] convenções românticas da poesia primitiva" (CANDIDO, 1993, p. 103), com as quais foi possível cantar o índio e a nossa exuberante natureza como topos de maior apreço e valoração entre os românticos. Acontecia, porém, que, para a formação do gênero romance entre nós, na época havia os embaraços de não termos modelos, pois nossa realidade era tão era diversa da europeia que as tentativas de nossos autores seguirem a filiação romântica exigiam estratégias peculiares. Sobre a tarefa de formar uma literatura que fosse nacional fez Antônio Candido (2002) relata:

O Romantismo brasileiro foi inicialmente (e continuou sendo em parte até o fim) sobretudo nacionalismo. E nacionalismo foi, antes de mais nada, escrever sobre coisas locais. Daí a importância da narrativa ficcional em prosa, maneira mais acessível e atual de apresentar a realidade, oferecendo ao leitor maior dose de verossimilhança e, com isso, aproximando o texto da sua experiência pessoal. (CANDIDO, 2002, p. 39-40).

$\mathrm{Na}$ variedade de temas e assuntos figurados em sua vasta obra, José de Alencar afirma esse nacionalismo no romance indianista, no regionalista e também num outro tipo de nacionalismo, mais de cunho urbano, nos romances Lucíola (1862) e Senhora (1874), nos quais tenta reproduzir, no plano da figuração, a sociedade que vivia em torno da corte na cidade do Rio de Janeiro em meados do século XIX e sua realidade circundante - bairros, ruas e ambientes cujos retratos contribuem para ancorar a verossimilhança que sustenta a obra. $\mathrm{O}$ 
autor procura oferecer, ao seu leitor, a verossimilhança da própria produção sociocultural da sexualidade pequeno-burguesa, configurando experiências amorosas e práticas aceitas dentro dos costumes da antiga capital. Por isso os exemplos vêm temperados de comentários pedagógicos para a educação das mulheres, comentários postos na fala da própria protagonista, que avisa sobre riscos que uma mulher enfrenta fora da proteção patriarcal. José de Alencar acreditava que, assim, estaria ajudando a melhorar a sociedade brasileira de então. A personagem é plasmada, desde o começo do romance, dentro da lógica pastoral do arrependimento e do sofrimento físico e psíquico impostos à mulher pecadora. Tal qual Maria Madalena, Lúcia/Lúcifer será redimida pelo amor que sente por Paulo, ainda que as dores e a febre do aborto retido sejam penitências para a sua caminhada rumo à redenção pela morte. $\mathrm{O}$ excerto a seguir é parte dessa catequese que possibilita que a personagem Paulo possa endereçar o romance a uma senhora leitora.

— Se eu pudesse viver, haveria forças que me separassem de ti? Haveria sacrifício que eu não fizesse para comprar mais alguns dias da minha felicidade? Mas Deus não quis. Sinto que a vida me foge!

A instâncias minhas bebeu finalmente o remédio, que nenhum efeito produziu. A febre lavrava com intensidade; eu já não tinha esperanças.

— O remédio de que eu preciso é o da religião. Quero confessar-me, Paulo.

Lúcia tomou os sacramentos com uma resignação angélica. (ALENCAR, 1988, p. 90).

Aqui vemos a personagem cumprir à risca o corolário carola, imponente o bastante para, 70 anos depois, ainda fazer o protagonista Paulo Honório, no romance São Bernardo, expor seu pensamento numa frase que revela o motivo dos seus ciúmes e das suas desconfianças de Madalena, sua mulher: "Sei lá! Mulher sem religião é capaz de tudo" (RAMOS, 1981, p. 131). Madalena irá sucumbir porque teve a coragem que a protagonista Lúcia não teve e nem podia ter dentro das suas condições de possibilidades.

Não apenas nesse romance, mas em toda a sua obra, José de Alencar se esmerou em "dilatar" a fé cristã, especialmente para leitoras, animando-as com um imaginário nacional/religioso que circunscrevia os limites da moralidade cristã burguesa. Em Lucíola (1862), a empreitada é feita com a retomada da efabulação à moda brasileira do motivo da "cortesã". Assim Lúcia será nossa primeira cortesã de papel, embora o motivo já fizesse parte da literatura europeia, criadora do modelo que José de Alencar repetiu sem nenhuma diferença de visada crítica, apenas bordando o modelo com as cores locais da nacionalidade, em cujas frinchas deixa expostas o duplo padrão moral e as hipocrisias da moralidade brasileira. Demorou apenas cinco meses que a cortesã - como motivo romanesco - chegasse ao Rio de Janeiro numa espécie de tradução do romance A Dama das Camélias (1848), de Dumas Filho. Não cabe aqui circunstanciar a recepção da obra de Dumas Filho em Paris e na França, mas a nossa recepção a Lucíola foi marcada por percalços e apenas nos meses de julho e 
agosto de 1853 esse romance foi, em partes, publicado como folhetim no periódico semanal O Jornal das Senhoras. Seja como for, pelo tom e escolha das palavras do jornal Diário do Rio de Janeiro, podemos visualizar como o motivo da cortesã era inquietante e provocador.

\begin{abstract}
A Dama das Camélias é uma severa lição de moral, que nos deixa ver sob as rosas do vício os agudos espinhos que dilaceram a alma criminosa, que nos mostra a felicidade fugindo a essas que não ouvem a voz da virtude; a miséria e a infâmia afogando nos braços a quem se desvia do caminho da honra. (Diário do Rio de Janeiro, 7 fev. 1856, p. 2).
\end{abstract}

Obviamente que o topos da cortesã só têm razão de existir dentro da sociedade patriarcal e dentro de um frequentão puritano guiado pelos mores do patriarcalismo e, no caso brasileiro, de um patriarcalismo provinciano e atávico, acostumado a considerar o corpo feminino com o abuso que impunha ao corpo da mucama. Nesse contexto, como fazer que uma mulher tão exposta ao achincalhe público como a prostituta fosse matéria de um romance?

José de Alencar encontrou a saída no resgate da convenção poética do amor cortês, amor esse que valoriza e louva a mulher, mesclando-a com o motivo da mulher prostituída, a cortesã ${ }^{3}$, que, séculos depois da "dona” louvada e respeitada pela convenção do amor cortês, passou a ser a frívola desfrutável que assegurava a diversão para os nobres da corte.

Em ambas as convenções cabia à mulher ser objeto de prazer e discurso dos homens e apenas poderia ser resgatada pelo amor de um homem. Dentro dessa ambientação patriarcalista. Alencar figura diversas situações que reforçam, expõem e confirmam os valores patriarcais da sociedade burguesa, retratando em Lucíola a impudicícia de uma moderna Eva, a quem o autor inocula na voz um discurso patriarcal mais rancoroso e autoritário que o proferido pelos personagens masculinos da obra. De fato, o discurso de Lúcia chega às raias da misoginia, como vemos pelas falas das personagens:

Ora! Há tanta mulher bonita! Qualquer destas vale mais do que eu, acredite! Demais, quando tiver bebido alguns copos de clicot e sentir-se eletrizado, saberá o senhor de quem são os lábios que toca? Qual? É uma mulher! Uma presa em que ceva o apetite! Que importa o nome? Sabe porventura o nome das aves e dos animais que lhe preparam esta ceia? Conhece-os?... Nem por isso as iguarias lhe parecem menos saborosas. (ALENCAR, 1988, p. 27).

\footnotetext{
3 “A partir do Renascimento fundem-se no termo 'cortesã' os conceitos da palaciana e da prostituta. A diferença é meramente econômica: a prostituta vive na rua ou n’um bordel com muitas outras, recebe vários clientes e é submetida a um cáften; a cortesã está muito bem estabelecida financeiramente, tem um ou poucos clientes, possui morada própria e não se submete a alguém. Ambas compartilham a origem miserável — são poucas as exceções —, mas esta foi escolhida pela sorte. A prostituta rica passa a ser denominada "cortesã" por adquirir o comportamento das damas da aristocracia e por fazer-se presente - de forma clandestina ou não - no mesmo círculo. Como não possuía título de fidalguia a distingui-la, talvez inicialmente fosse apontada, e não sem ironia, como 'aquela cortesã'” (GRIFFIN, Susan. O livro das cortesãs: um catálogo das suas virtudes. Rio de Janeiro: Rocco, 2003, p. 57).
} 
Vemos aqui um quê de ironia de quem tem plena consciência de seu lugar na sociedade e do seu corpo como coisa. Essa percepção demonstra que a personagem vivia entre o drama da revolta contra a sua condição social. Essa atitude ambivalente é o fio da navalha que anima o entrecho e, ao mesmo tempo, os afetos do leitor, levando escritor, personagens e leitores a experimentar a vida na corte imperial tendo por veículo um romance urbano verossímil carioca.

\section{MARIA DA GLÓRIA, LÚCIA-LÚCIFER, BOA MARIA OU MARIA ANGELICAL}

Lucíola (1862) faz parte da ficção urbana de Alencar. Poderíamos resumir a fábula dizendo que nela são narradas as aventuras (ou desventuras) de uma cortesã carioca que, desde os seus quatorze anos de idade, foi levada a se prostituir para garantir a sua sobrevivência e a da sua família. Acontece que não é assim que Paulo, o narrador da história, no-la apresenta nos primeiros capítulos do romance. De fato, da maneira como o entrecho é construído, parece que o romancista usou do expediente do "ser" e do "parecer ser" como uma espécie de suspense para prender o leitor. Essa afirmação pode ser comprovada logo na primeira aparição da personagem. O que vemos? Vemos uma moça recatada, muito bonita, inocente, a passear sozinha, mas o realce da figura faz com que o leitor, assim como a personagem-narrador não perceba que ela está sozinha, pois, como as mulheres não andavam sozinhas na época, esse detalhe-chave da cena torna-se uma pista de que não estamos diante uma donzela. Desponta, nessa cena, a dubiedade a ser mantida em todo o desenrolar do romance, pois ora a vemos corrompida e dissoluta, capaz de gozar dos prazeres do corpo com diversos homens, cheia de caprichos, perdulária e infernal, ao ponto de ficar nua sobre uma mesa, expondo-se à cobiça de muitos olhares masculinos, ora a vemos pura e cândida.

Assim escondida sob o retrato dessa Lilith brasileira, aos poucos o narrador vai nos desnudando uma outra figura, que se esconde sob a aparência pervertida, e essa figura é a de uma mocinha cujo nome Maria é a face cristã da outra Eva - a Eva pura e imaculada, porque virgem de alma. É lógico que, para a mentalidade coletiva da época, o corpo corrompido deverá arder nas profundas dos infernos, isso para que a alma pura seja completamente redimida. Depois de a ter pintado dissoluta, Paulo, que foi a razão de sua salvação e desgraça, começa, aos poucos, a apresentar, no palco da diegese ${ }^{4}$, a história de vida de Lucíola anterior à entrega aos prazeres carnais. Ficamos sabendo que ela levava uma vida simples, pacata e oculta, ou seja, efetivamente modesta e completamente dentro do estereótipo patriarcal cristão que o Romantismo adota como preciosidade. Essa primeira Lucíola era Maria da Glória.

Então a primeira Lucíola - a Maria da Glória - foi sucedida por Lúcia-Lucífer, que é a Lucíola do período em que ela havia se entregado à vida dissoluta, à concupiscência, à luxúria e aos excessos de valorização dos bens materiais. A partir desse ponto vemos surgir uma mulher terceira mulher, muito diferente das anteriores. Essa agora será a terceira identidade

4 Segundo o Dicionário de Termos Literários de Carlos Ceia, diegese "é um termo de origem grega divulgado pelos estruturalistas franceses para designar o conjunto de acções que formam uma história narrada segundo certos princípios cronológicos". Disponível em: <http://edtl.fcsh.unl.pt/business-directory/6734/diegese/>. Acesso em: 14 dez. 2016). 
assumida pela protagonista, a boa Maria ou Maria angelical, nas palavras de Paulo. Então essa terceira e última mulher irá renegar todos os prazeres mundanos e não se deixará mais tocar pelo desejo sexual e nem por mãos masculinas. Trata-se agora de uma beata que, de modo edificante, caminha rumo à elevação e à redenção, mas, como o patriarcalismo da época era inexorável com as mulheres que ousavam sair do seu corolário, cabe a ela a morte como forma de expiação de sua culpa.

Conforme narra Paulo, ao analisar ele a própria experiência amorosa, primeiramente vemos a pobre Maria da Glória sendo obrigada a se prostituir em prol da saúde de sua família. Dessa primeira fase vemos o fulcro na passagem do grosseiro desenrolar de algumas angústias, e o início de outras, quando, em busca de ajuda, ela acompanha o agiota Couto, que lhe deu algumas moedas de ouro em troca de sexo:

Ele tirou do bolso algumas moedas de ouro, sobre as quais me precipitei, pedindo-lhe de joelhos que mais desse para salvar minha mãe; mas senti os seus lábios que me tocavam, e fugi. Oh! Não posso contar lhe que lata foi a minha: três vezes corri espavorida até a casa, e diante daquela agonia sentia renascer a coragem, e voltava. Não sabia o que queria esse homem; ignorava então o que é a honra e a virtude da mulher - o que se revoltava em mim era o pudor ofendido. Desde que os meus véus se despedaçaram, cuidei que morria; não senti nada mais, nada, senão o contato frio das moedas de ouro que eu cerrava na minha mão crispada. O meu pensamento estava junto do leito de dor, onde gemia tudo o que eu amava neste mundo. (ALENCAR, 1988, p. 97).

A menina, que antes se detinha a ensinar francês ao irmão e de aprender a tocar piano, agora estava diante de uma grande decisão que a fez ter o pudor ofendido. A inquietude de tudo isso não se deve ao fato de ela ter se prostituído, mas ao modo como seu pai reagiu no momento da confissão da forma como ela tinha conseguido as moedas: a expulsão de sua própria casa por aquele que ela tinha vendido a sua pureza para salvá-lo. Maria da Glória foi arrancada da sua sublimidade e, como recompensa, ganhou a desolação de sua família, do seu caráter e de sua vida. Ela expressa a hipocrisia burguesa e machista a que as mulheres eram submetidas em sua época.

Numa segunda etapa de sua história, vemos o despertar das paixões carnais na mulher Lúcia, já sexualmente experiente e cheia de pruridos ao constatar que também tinha prazer no ato sexual com seus clientes. A citação abaixo é um primor do cerceamento que a moral patriarcal impõe às mulheres:

[...] mais horrível era quando nos braços de um homem este corpo sem alma despertava pelos sentidos. Oh! Ninguém pode imaginar! Queria resistir e não podia! Queria matar-me trucidando a carne rebelde! Tinha instintos de fera! Era uma raiva e desespero, que me davam ímpetos de estrangular um algoz. Passado esse suplício restava uma vaga sensação de dor e um rancor profundo pelo ente miserável que me arrancara o prazer das entranhas convulsas. (Ibid., p. 111). 
Eis então que esse rancor não a impede de desfrutar dos prazeres sexuais e de se tornar uma mulher pública, obstinada e rica. Como é sabido, a sexualidade, desde o início da era cristã, foi o símbolo do pecado por excelência, pecado que só pode ser saldado através da morte. Lucíola era, para os seus admiradores, a própria expressão do pecado, era Lúcifer (o mais belo dos anjos criados por Deus e que depois se revolta e torna-se chefe dos demônios), vista única e exclusivamente como um objeto sexual, indigna de ser chamada de "senhora", principalmente por lhe faltar um marido, um irmão ou um pai, pois seriam eles que garantiriam sua integridade. Segundo Delumeau (1990), a mulher foi acusada pelo seu oposto de ter sido aquela que introduziu na Terra o pecado, a desgraça e a morte, sendo até relacionada com Pandora; a mulher foi o mal terreno, ou seja, o mal da terra dos homens:

Pandora grega ou Eva judaica, ela cometeu a falta original ao abrir a urna que continha todos os males ou ao comer o fruto proibido. O homem procurou um responsável para o sofrimento, para o malogro, para o desaparecimento do paraíso terrestre, e encontrou a mulher. Como não temer um ser que nunca é tão perigoso como quando sorri? A caverna sexual tornou-se a fossa viscosa do inferno (DELUMEAU, 1990, p. 314).

Além disso, é notável que Alencar coloca Lucíola como uma exibicionista de sua riqueza, que exibe a todos sua condição financeira através dos seus objetos pessoais, trajes e refino pessoal:

Lúcia fitou-me por muito tempo, e chegou-se ao espelho para dar os últimos toques ao seu traje, que se compunha de um vestido escarlate com largos folhos de renda preta, bastante decotado para deixar ver as suas belas espáduas, de um filó alvo e transparente que flutuava-lhe pelo seio cingindo o colo, e de uma profusão de brilhantes magníficos capaz de tentar Eva, se ela tivesse resistido ao fruto proibido. (ALENCAR, 1987, p. 71 apud COUTO, 2010).

Para a sociedade patriarcal do século XIX, tomando como base a religiosidade cristã, a mulher era responsável pelos serviços domésticos, pela reprodução, pela educação e cuidado dos filhos e pela boa moral, que podemos entender como "virgindade", que era sinônimo de uma mulher honesta. Ou seja, o caráter estava relacionado com a integridade do phallós femininum ${ }^{5}$. Aquelas que transgredissem tais padrões sociais eram vistas de outra maneira, e eram indignas do amor.

A moral e o bom costume, contudo, fazem parte de um constructo social, ou seja, decorrem dos padrões estabelecidos e são a reprodução de um padrão que molda a sociedade, legitimando determinadas condutas como forma de impor, por meio das relações de poder, um molde que agrade ao grupo que impõe tais valores. É sob essa perspectiva que podemos dispor de dois vieses do olhar de Paulo para Lúcia: a descrição que ele fez dela quando a viu pela primeira vez, e o seu olhar após a fala de Sá, em que Sá diz a Paulo que aquela era uma mulher indigna de ser chamada de "senhora":

5 Falo feminino. 
A lua vinha assomando pelo cimo das montanhas fronteiras; descobri nessa ocasião, a alguns passos de mim, uma linda moça, que parara um instante para contemplar no horizonte as nuvens brancas esgarçadas sobre o céu azul e estrelado. Admirei-lhe do primeiro olhar um talhe esbelto e de suprema elegância. $\mathrm{O}$ vestido que a moldava era cinzento com orlas de veludo castanho e dava esquisito realce a um desses rostos suaves, puros e diáfanos, que parece vão desfazer-se ao menor sopro, como os tênues vapores da alvorada. Ressumbrava na sua muda contemplação doce melancolia e não sei que laivos de tão ingênua castidade, que o meu olhar repousou calmo e sereno na mimosa aparição (Ibid., p. 14).

- Quem é esta senhora? Perguntei a Sá. [...]

- Não é uma senhora, Paulo! É uma mulher bonita. Quer conhecê-la? Compreendi e corei de minha simplicidade provinciana, que confundira a máscara hipócrita do vício com o modesto recato da inocência. Só então notei que aquela moça estava só, e que a ausência de um pai, de um marido, ou de um irmão, devia-me ter feito suspeitar a verdade. (Ibid., p. 15).

Qual foi o motivo de Paulo ter mudado a forma de ver Lúcia? Evidentemente ele, apoiando-se no constructo social da época, passou a ver a protagonista sob outra perspectiva. Mesmo assim, contudo, durante a obra, podemos encontrar vários momentos em que Paulo fica diante de um paradoxo, e não sabe se sente atração ou repulsa por Lúcia:

O próprio Paulo apresenta um comportamento paradoxal. Há momentos em que ele deseja possuir Lúcia de uma forma violenta e há outros em que promete respeitá-la; às vezes ofende-a e logo depois suplica-lhe perdão. Ele vê em Lúcia uma prostituta refinada e, ao mesmo tempo, uma menina de quinze anos, pura e cândida. (FERNANDES, 2009, p. 28).

Delumeau (1990) traz, em seu livro, sete pontos em que a mulher é criticada na obra "De planctu ecclesiae" 6 . Dentre os sete pontos, podemos destacar o segundo:

Ela trai homens por meio de chamarizes mentirosos a fim de melhor arrastá-los para o abismo da sensualidade. Ora, "não há nenhuma imundície para a qual a luxúria não conduza”. Para melhor enganar, ela se pinta, se maquia, chega até a colocar na cabeça a cabeleira dos mortos. Fundamentalmente cortesã, gosta de frequentar as danças que acendem o desejo. Transforma "o bem em mal", "a natureza em seu descontrário", especialmente no domínio sexual. (DELUMEAU, 1990, p. 323).

6 PAES, Álvaro. A Igreja está de Luto. 1474. 
Nessa citação encontramos a visão que a Igreja expressa em 1400, que se estende até o século XXI, sobre a cortesã: a mulher como arma do diabo para instaurar o pecado na terra. Todo o paradoxo vivido por Paulo pauta-se nessa visão fechada, preconceituosa e machista da época: a personagem queria doar seu amor para Lúcia, mas era acometido de uma desconfiança por conta de toda a construção social de que as cortesãs tinham na época, e principalmente pela ideia de que tal mulher jamais se apaixonaria por um homem, e que um homem, qualquer homem, lhe serviria exclusivamente como fulcro do prazer:

Paulo e Lúcia são, portanto, representações de uma época, figuras socioliterárias que expressam a visão de Alencar sobre a figura da prostituta no século XIX. Assim como Lúcia, as prostitutas são mulheres fortes, pois vivenciam a todo momento preconceitos e mais preconceitos e a sociedade, por sua vez, é incapaz de se solidarizar com o seu drama. Lucíola é, portanto, uma denúncia à mesquinhez da sociedade que julga as prostitutas como mulheres impuras, mas delas usufruem em benefício próprio, continuando a sustentar a classe, no momento em que são pagas pelos "serviços prestados" (FERNANDES, 2009, p. 44).

Na última etapa, Maria, agora renovada, vivencia o período em que ocorre o desprendimento de Lúcia-Lúcifer e o retorno à sua essência de "Maria da Glória" inicial. A trama, que até então marcava um ritmo nervoso, agora era substituída pela calmaria e o leitor passa a conhecer a interpretação da história de Lúcia e seus desfechos a partir da perspectiva da protagonista, que até então era narrada por Paulo. Essa mudança de perspectiva narrativa provoca no leitor uma mudança no sentimento que ele nutria contra a cortesã que, com certeza, já a estava julgando a partir de suas experiências e vivências pessoais.

É a partir de um pouco mais da metade do livro que Lúcia abandona os luxos e precisa da ajuda de Paulo para superar os obstáculos de sua vida. Sai do meio social movimentado do Rio de Janeiro e vai morar no campo, junto com sua irmã, em uma casa simples. Segundo Couto (2010), obviamente, uma mulher que antes era exibicionista e agora está vivendo de forma reservada, fez com que a sociedade voltasse os olhos para Lucíola e não aceitasse docilmente tal mudança, partindo do pressuposto de que uma pessoa dedicada ao exibicionismo seria impossível de viver discretamente:

- Não tens sido vista nos teatros e passeios, já não tens um carro; não és enfim a mulher do tom que eu ainda conheci!

- Aborreci-me de tudo isto!

- Não te podes aborrecer sem que o mundo repare!

- Como! Não sou senhora de viver a seu modo, desde que com isso não faço mal a ninguém? Se apareço; é um escândalo; se fico no meu canto, ainda se ocupam comigo. 
- Que queres! Há certas vidas que não se pertencem, mas à sociedade onde existem (ALENCAR, 1987, p. 67 apud COUTO, 2010).

A renovação de Lúcia ocorre com a sua própria punição contra a visão que a sociedade tinha da cortesã. Ocorre a ascensão novamente de Lúcifer a Anjo de Deus.

Sob essa óptica, constrói-se, pois, a figura da prostituta na protagonista do romance Lucíola. Seria Lúcia anjo ou mulher fatal? A pureza de seus sentimentos e de sua alma a transformaram em uma figura angelical, mas essa mulher bonita e sedutora é marcada também por uma vida de luxúria e devassidão. Entretanto, acima dessas características, está Lúcia, que, com todas as suas idiossincrasias, é uma mulher forte e corajosa, que não pode viver em uma sociedade tão injusta. (FERNANDES, 2009, p. 45).

Segundo Macedo \& Alves;

O final inesperado e a concretização do amor transfigurador e purificador contornam de idealização romântica a despedida dos amantes. (...) A morte em Lucíola é a sentença final que, separando radicalmente a matéria física, une a matéria espiritual. Desse modo, a morte é vista como uma purgação aos pecados cometidos por Lúcia. Purgação que a levará ao seu destino final: separada da carne que leva ao pecado carnal, segundo a tradição cristã, Lúcia pode entregar o seu espírito a Paulo. (MACEDO \& ALVES, [19??], p. 7).

Considerando o puritanismo e o provincianismo da corte carioca de então, é de esperar que o único final possível para esse romance seja a separação do casal e a morte de Lucíola. Ainda mais porque ela engravida de Paulo. Espera uma criança que não pode nascer e ambos morrem. Se, de alguma forma, Alencar tivesse livrado Lúcia de sua morte, substituindo os erros por um final feliz, o seu passado ainda estaria vivo e prendendo-a, tolhendo sua liberdade. Foi apenas a morte, como uma forma de libertação, que pôde, enfim, fazer o espírito de Lúcia se libertar e se desprender da matéria para trazê-la à essência angelical que havia sido perdida. Lucíola, enfim, era livre!

\section{CONSIDERAÇÕES FINAIS}

A obra analisada, ainda que a contrapelo, expõe o pensamento machista e até mesmo misógino que ainda nos dias de hoje domina o discurso que anima a vida social no Brasil. É lamentável que ainda hoje esse discurso, tão veementemente marcado nas palavras da protagonista dum romance do século XIX, continue sendo reiterado hoje, à farta, por grande parte das mulheres. Tal discurso persiste tanto na sociedade brasileira a ponto de ser preciso apresentar políticas públicas para combater os assassinatos de mulheres por homens com os quais elas mantinham laços afetivos, assim como Lucíola com Paulo. Para marcar a 
gravidade e a extensão dos dados estatísticos desses assassinatos foi criada a etiqueta semiótica "feminicídio". Talvez ainda precisemos da Lei Maria da Pena em todo o presente século. Nesse sentido, a mulher representada pela personagem Lucíola é um péssimo exemplo para a educação sentimental das mulheres e dos homens. A esse seu discurso e à sua morte cabem como luva as palavras de Lourdes Bandeira, socióloga, pesquisadora e professora da Universidade de Brasília:

[...] o feminicídio representa a última etapa de um continuum de violência que leva à morte. Seu caráter violento evidencia a predominância de relações de gênero hierárquicas e desiguais. Precedido por outros eventos, tais como abusos físicos e psicológicos, que tentam submeter as mulheres a uma lógica de dominação masculina e a um padrão cultural de subordinação que foi aprendido ao longo de gerações". ${ }^{7}$

Ainda que consideremos o momento histórico em que o romance foi escrito, e embora saibamos que as ações e situações descritas no romance revelam que era algo comum à época, em que “[...] o sujeito 'aceitava' essa realidade como algo natural e invariável, a natureza precária do indivíduo como herança intransponível [...]” (JACOMEL \& SILVA, 2007, p. 740), não podemos nos esquecer de que José de Alencar fazia parte da elite pensante da época e, nessa condição, poderia deveras ter contribuído para uma cultura menos autoritária e machista, se tivesse uma visada crítica como tiveram, antes deles, Martins Pena, em Juiz de Paz da Roça (1833), por exemplo. Como, porém, era um autor que, nas suas próprias palavras, escrevia sob a égide da "musa industrial", o propósito de ser aceito pelos seus leitores e não de questionar seus costumes e discurso contribuiu para a permanência e a manutenção do patriarcalismo, do machismo e da misoginia, que, por mais estranho que possa parecer, em lugar de diminuir ou acabar, continuam, dois séculos depois, intrinsecamente ligados à vida social da atualidade.

A mulher do século XXI ainda continua sendo tolhida e vista como um objeto sexual pelos homens, que insistem em propagar o machismo através das mais variadas formas. Se compararmos a cortesã Lucíola, que foi idealizada à sombra da realidade da época - há mais de 150 anos -, com uma cortesã da atualidade, constataremos que, independentemente de haver ou não um motivo para ela se dedicar à prostituição, ela é taxada por toda a sociedade como uma mulher indigna, impura, e isso que remete ao ódio. A vida íntima entrelaça-se à pública e passam a ser uma só, sendo julgadas simultaneamente.

José de Alencar figurou no romance Lucíola toda a opressão às mulheres e todo o autoritarismo e atavismo com os quais a sociedade retratada controlava a vida da mulher do século XIX. Lúcia, em sua morte, é salva de suas “máculas”. Fora da ficção, quantas mulheres brasileiras ainda precisarão morrer até que possamos quebrar as correntes desse controle?

7 Disponível em: <http://www.compromissoeatitude.org.br/feminicidio-a-ultima-etapa-do-ciclo-da-violen cia-contra-a-mulher-por-lourdes-bandeira/>. Acesso em: 11 dez. 2016. 


\section{REFERÊNCIAS}

ALENCAR, José de. Lucíola. 10. ed. São Paulo: Editora Ática, 1987.

Lucíola. 12. ed. São Paulo: Editora Ática, 1988.

CANDIDO, Antônio. O romantismo no Brasil. São Paulo: Humanitas, 2002.

COUTO, Marília. A estética romântica em Lucíola, de José de Alencar. Revista Leitura e Escrita, nº 2, jan./jun. 2010. Disponível em: <http://www.leituraeescritura. com/revista/le_02a.htm >. Acesso em: 5 dez. 2015.

DELUMEAU, Jean. História do medo no Ocidente 1300-1800: uma cidade. Trad. Maria Lúcia Machado; Trad. de notas Heloísa Jahn. São Paulo: Companhia das Letras, 2009.

FERNANDES, Alcinda Lima dos Anjos. As mulheres em José de Alencar: Lucíola e Senhora. Disponível em: <http://pdf.thepdfportal.net/?id=363335>. Acesso em: 20 out. 2015.

GRIFFIN, Susan. O livro das cortesãs: um catálogo das suas virtudes. Rio de Janeiro: Rocco, 2003.

MACEDO, F. I. O.; ALVES, J. H. P. . O significado da morte em Lucíola de José de Alencar e em O voo da guará vermelha de Maria Valéria Rezende.. In: XI Colóquio Representação de Gênero e de Sexualidade, 2015, Campina Grande. Educação, Políticas de corpo e modos de subjetivação. Campina Grande: Editora Realize, 2015. Disponível em: <https:/editorarealize.com.br/revistas/conidis/ trabalhos/TRABALHO_EV074_MD1_SA13_ID2234_23102017183140.pdf >.. Acesso em: 5 dez. 2015.

RAMOS, Graciliano. São Bernardo. Rio de Janeiro: Record, 1981. p. 131. 